\title{
Decoding the temporal nature of brain GR activity in the NFKB signal transition leading to depressive-like behavior
}

\author{
Young-Min Han ${ }^{1}$ - Min Sun Kim ${ }^{1}$ Juyeong Jo ${ }^{1}$ Daiha Shin ${ }^{1}$ - Seung-Hae Kwon ${ }^{1}$ Jong Bok SEO ${ }^{1}$ \\ Dongmin Kang $\mathbb{D}^{2} \cdot$ Byoung Dae Lee ${ }^{3} \cdot \mathrm{Hoon} \mathrm{Ryu}^{4} \cdot$ Eun Mi Hwang ${ }^{5} \cdot$ Jae-Min Kim ${ }^{6}$ - Paresh D. Patel ${ }^{7}$. \\ David M. Lyons ${ }^{8} \cdot$ Alan F. Schatzberg ${ }^{8} \cdot$ Song Her $\mathbb{1}^{1}$
}

Received: 3 January 2020 / Revised: 17 November 2020 / Accepted: 5 January 2021 / Published online: 22 January 2021

(c) The Author(s) 2021. This article is published with open access

\begin{abstract}
The fine-tuning of neuroinflammation is crucial for brain homeostasis as well as its immune response. The transcription factor, nuclear factor- $\kappa-\mathrm{B}(\mathrm{NF \kappa B})$ is a key inflammatory player that is antagonized via anti-inflammatory actions exerted by the glucocorticoid receptor (GR). However, technical limitations have restricted our understanding of how GR is involved in the dynamics of $\mathrm{NF \kappa B}$ in vivo. In this study, we used an improved lentiviral-based reporter to elucidate the time course of $\mathrm{NF \kappa B}$ and GR activities during behavioral changes from sickness to depression induced by a systemic lipopolysaccharide challenge. The trajectory of NFKB activity established a behavioral basis for the NFKB signal transition involved in three phases, sickness-early-phase, normal-middle-phase, and depressive-like-late-phase. The temporal shift in brain GR activity was differentially involved in the transition of NFKB signals during the normal and depressive-like phases. The middle-phase GR effectively inhibited NFKB in a glucocorticoid-dependent manner, but the late-phase GR had no inhibitory action. Furthermore, we revealed the cryptic role of basal GR activity in the early NFkB signal transition, as evidenced by the fact that blocking GR activity with RU486 led to early depressive-like episodes through the emergence of the brain NFKB activity. These results highlight the inhibitory action of GR on NFkB by the basal and activated hypothalamic-pituitaryadrenal (HPA)-axis during body-to-brain inflammatory spread, providing clues about molecular mechanisms underlying systemic inflammation caused by such as COVID-19 infection, leading to depression.
\end{abstract}

\section{Introduction}

A growing body of evidence suggests that inflammation has a pathophysiological role in depression. During inflammatory processes, nuclear factor- $\mathrm{k}-\mathrm{B}(\mathrm{NF \kappa B})$ plays a major

Supplementary information The online version contains supplementary material available at https://doi.org/10.1038/s41380021-01016-1.

Song Her

swher@kbsi.re.kr

1 Seoul Centre, Korea Basic Science Institute, Seoul, South Korea

2 Department of Life Science, Ewha Womans University, Seoul, South Korea

3 Department of Physiology, School of Medicine, Kyung Hee University, Seoul, South Korea

4 Neuroscience Centre, Korea Institute of Science and Technology, Seoul, South Korea role in cellular responses to a wide variety of stimuli. As a counterpart, when glucocorticoid receptors (GRs) bind glucocorticoids (GCs), they exert essential immunosuppressive and anti-inflammatory actions. Therefore, it has been postulated that dysfunctional GR activity causes depression, due to crosstalk problems between NFKB and $\mathrm{GR}$, as shown in our previous reports on dampened GR activity [1]. In the study on their targeted transcripts, however, the exact brain mechanisms of this crosstalk have remained unresolved by jumbled gene expressions caused

5 Center for Functional Connectomics, Korea Institute of Science and Technology, Seoul, South Korea

6 Department of Psychiatry, Chonnam National University Medical School, Seoul, South Korea

7 Department of Psychiatry, Molecular and Behavioral Neuroscience Institute, University of Michigan Medical Centre, Ann Arbor, MI, USA

8 Departments of Psychiatry, Stanford University Medical Centre, Stanford, CA, USA 
by different structures of their gene promoters [2, 3]. Individual variation particularly induced by endpoint analysis is another difficult barrier for crosstalk readings [4, 5]. Therefore, rather than attempting to investigate transcriptional NFKB-GR, we focused on the longitudinal monitoring of the signal NFKB-GR interplay using in vivo imaging techniques.

Although transgenic reporter mice are an alternative solution to the direct monitoring of biological processes $[6,7]$, in vivo real-time monitoring of their activation has been inaccessible, partly due to the difficulty in spatial resolution, that could describe such events. Their clonal ubiquity leads to poor special resolution and severely impedes pinpoint monitoring of transcriptional activity. Particularly, spacious bioluminescence is a major disadvantage in studying anatomical brain function in which those functions can be attributed to different regions of the brain or even the same cell type $[8,9]$. Other strategies, such as Cre-Lox recombination [10] and the non-viral gene delivery system [11], also have unresolved problems with bioluminescence. Herein, using pinpoint stereotaxic injection with improved lentivirus-based luciferase (Luc) reporters, we identify the pinpoint dynamic activities of GR and $\mathrm{NFKB}$, allowing precise signal trajectories and timing of NFkB-GR interplay.

We targeted the infralimbic prefrontal cortex (IL-PFC, corresponding to the ventromedial PFC in humans) as a representative anatomical brain region associated with depression [12, 13]. The dermis was targeted as a representative body region in which various aspects of the immune system actively maintains skin homeostasis $[13,14]$. We used a lipopolysaccharide (LPS)-induced depressive mouse model that shows time-dependent behaviors such as early symptoms of sickness and late transient depressive-like behavior on a short timescale [15]. Understanding the NFkB-GR interplay during the behavioral outcomes helps to decipher the molecular mechanisms underlying the etiology of inflammationassociated depression.

\section{Method summary}

To monitor signal activity with the IVIS 200 imaging system (PerkinElmer Company, Alameda, USA), ICR mice were injected with one of the lentiviral reporters (NFkB-Luc2CP, GR-Luc2CP, or elongation factor (EF) $1 \alpha$-Luc2CP, Supplementary Fig. 1). Meanwhile, the cellular location of the signal was determined through immunohistochemical staining in which NFKB and GR signal activities were mainly detected in $\mathrm{NeuN}^{+}$neuronal cells in the IL-PFC (Supplementary Fig. 2). $[1,16]$. In the monitoring of $\mathrm{NFKB}$ and GR activities, three bioluminescence experiments were performed to investigate the LPS effect, the LPS effect on the RU486, or adrenalectomy (Supplementary Fig. 3b-d). The average signal obtained from different animals injected with the EF1 $\alpha$ Luc reporter was used as the reference for the normalization of two signals. The BLI data from an individual mouse, combined from three independent studies were analyzed by one- or two-way analysis of variance (ANOVA) tests, and the statistical significance between groups was determined by Sidak's multiple comparison test; otherwise, Student's $t$-test was used. Detailed materials and methods and associated references are provided in the Supplementary Information.

\section{Results}

\section{Distinguishing NFKB activation in the IL-PFC and dermis by an improved NFKB-reporter}

To monitor NFKB activity in vivo, first, we modified the previous lentiviral-based GR-Luc reporter by replacing $5 \times$ GRE-AIEP with a $6 \times$ NFKB-TATA DNA fragment, designated NFkB-Luc reporter (Supplementary Fig. 1a). During the monitoring of NFkB activity by bioluminescent signal image (BLI), however, we noticed that the reporter was insufficient for monitoring NFKB activation in the ILPFC or the dermis (Fig. 1a, b). The temporal resolution of the NFkB-Luc reporter, associated with the long half-life of luciferase [17], hindered the accurate monitoring of NFKB activation. Thus, we developed an improved NFkB-Luc2CP reporter by replacing Luc with Luc2CP as in the previously reported GRE-Luc2CP [16], expecting high temporal resolution with increased intensity. The monitoring of $\mathrm{NF \kappa B}$ activity with this improved reporter showed clear dermal NFKB activation at $2 \mathrm{~h}$ post-LPS; however, there was still no NFKB activation observed in the IL-PFC (Fig. 1c), which may be an in vivo evidence for different responses of NFKB in the IL-PFC and dermis. This difference was confirmed by a qPCR assay demonstrating decreased expression of NFKB-responsive genes (interleukin-1 $\beta$, granulocyte-macrophage colony-stimulating factor; GM-CSF, and tumor necrosis factor; TNF $\alpha$ ) (Supplementary Fig. $4 a, b)$. The lower NFkB response in the IL-PFC compared to the dermis was also confirmed, as evidenced by the left-shifted distribution of the 32 NFkBresponse gene expression (Supplementary M \& M and Supplementary Fig. 4c).

\section{Tissue-specific NFkB activation in behavioral outcomes}

To exclude possible errors from intra-individual variations, an NFKB dual-monitoring assay was performed on the ILPFC and dermis of the same subject up to $36 \mathrm{~h}$ post-LPS. As shown by the BLIs (Fig. 1d) and NFkB profiles (Fig. 1e), 
(a)

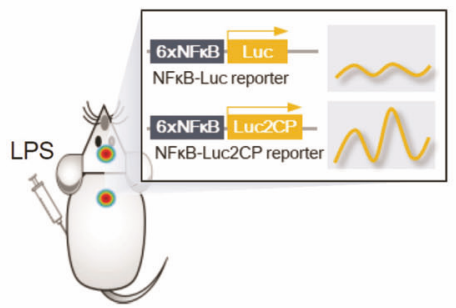

(b)

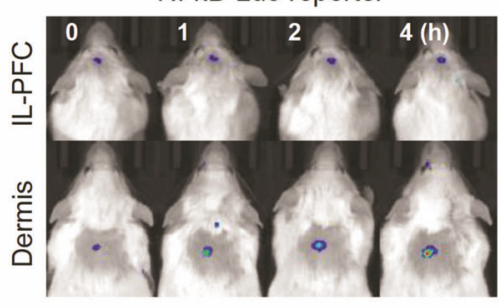

(c)

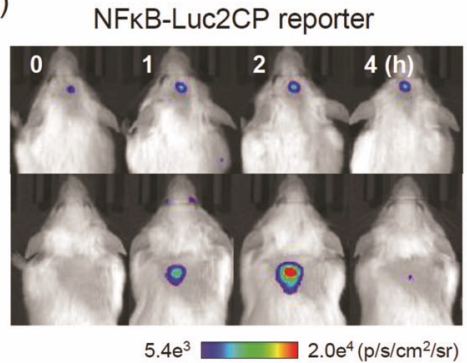

(d)

Dual monitoring of $\mathrm{NFKB}$ activity

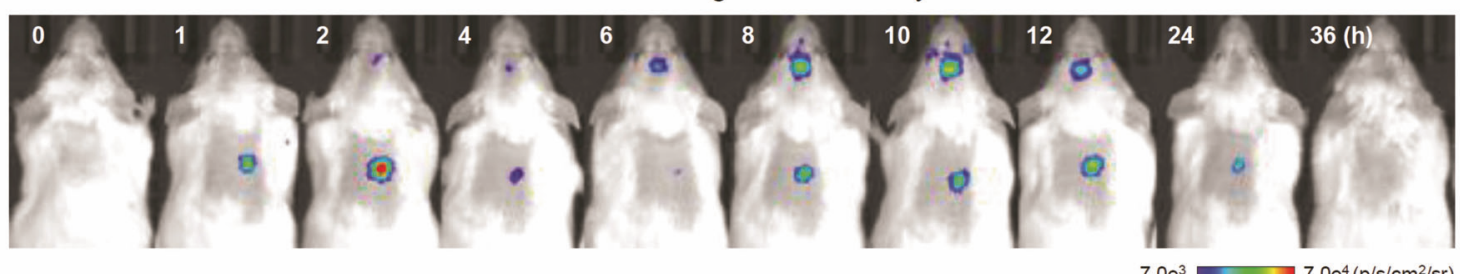

(e)

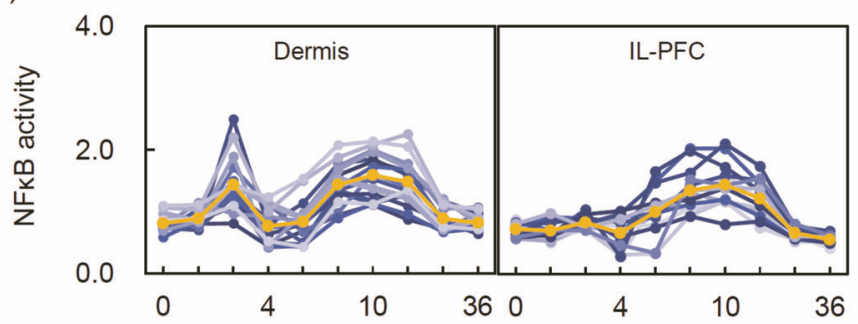

(g)

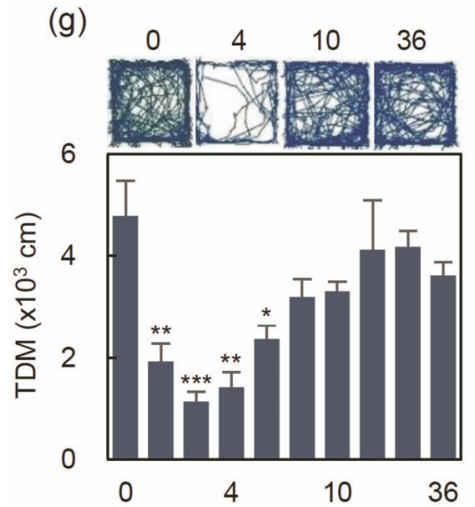

(h)

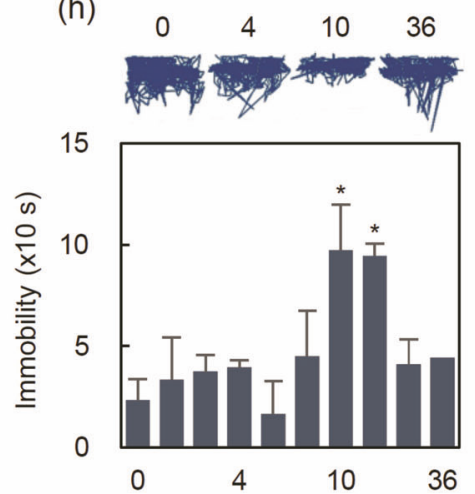

(f)

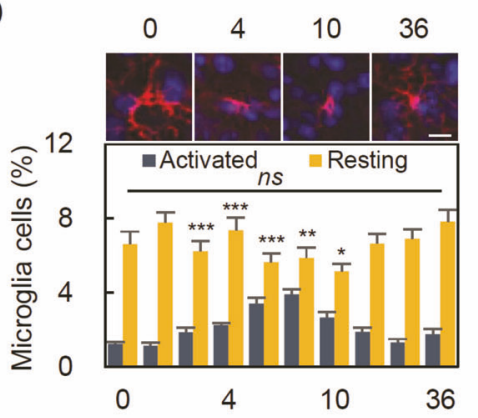

(i)

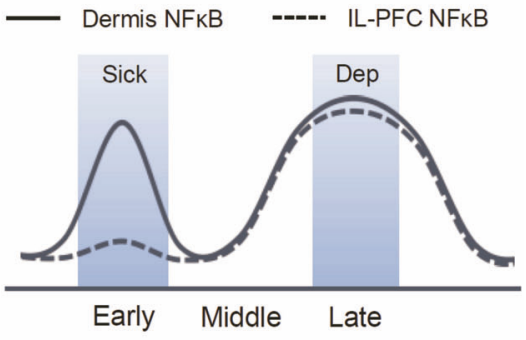

Fig. 1 Different NFкB responses in the IL-PFC and dermis. a Schematic illustrating an improved $\mathrm{NF}_{\mathrm{B}} \mathrm{B}$ reporter for the monitoring of dynamic transcriptional activity in a living mouse. Comparative

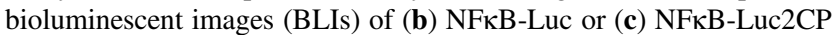
reporter. NFאB activity was monitored by single-monitoring in the IL-PFC or dermis after intraperitoneal injection of $1 \mathrm{mg} / \mathrm{kg}$ LPS.

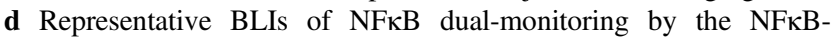
Luc2CP reporter. e Individual NFKB profiles of the dermis (left panel) and IL-PFC (right panel). The orange line represents the average $\mathrm{NF} \kappa \mathrm{B}$ activity at each time point $(n=13)$. f Representative fluorescence images of microglia (top, scale bar $=10 \mu \mathrm{m}$ ) and quantification of activated and resting microglia (bottom) in the IL-PFC.
Immunohistochemical staining with Iba1 and DAPI. Time course of behaviors for (g) total distance moved in the OFT and (h) immobility time in the FST with representative tracking paths. Data are represented as the mean \pm standard error of measurement $[n=8 /$ group, except for $6 \mathrm{~h}$ post-LPS in the OFT ( $n=7 /$ group) and $36 \mathrm{~h}$ post-LPS in the FST ( $n=7 /$ group)]. i The trajectories of the two NFkB activities. Statistical significance was determined by Student's $t$-test $(* P<0.05$, $* * P<0.01, * * * P<0.001, \mathrm{~ns}=$ non-significant vs control). IL-PFC infralimbic prefrontal cortex, Sick sickness behavior, Dep depressivelike behavior, FST forced swimming test, OFT open field test, TDM total distance moved. 
differential NFאB activation was verified. Two hours postLPS, dermal NFKB activity showed a clear peak, but no activity was shown in the IL-PFC. Two-way ANOVA with repeated measures (ANOVA RM) showed significant effects of tissue $\left(F_{1,24}=6.04, P<0.05\right)$, time $\left(F_{9,216}=\right.$ 22.28, $P<0.001)$, and tissue $\times$ time interaction $\left(F_{9,216}=\right.$ 5.52, $P<0.001)$. Sidak multiple comparison tests revealed that the $\mathrm{NF \kappa B}$ activity in the IL-PFC was significantly lower than in the dermis at $2 \mathrm{~h}$ post-LPS $(P<0.001$, mean difference $=0.69$ ). Meanwhile, during 8-12 h post-LPS, NFkB was equally activated in both the IL-PFC and dermis without significant difference $(P>0.05$ at 8,10 , and $12 \mathrm{~h})$. Immunohistochemical (IHC) analysis with IL-PFC tissues showed that activated microglial cells were also significantly increased during the late-phase (Fig. 1f).

Open field test (OFT) and forced swimming (FST) were performed at the indicated time points to elucidate sickness and depressive-like behavioral links to signal activities, respectively. Consistent with previous findings [18-20], the LPS challenge induced time-dependent behavioral outcomes, as shown an increase in OFT total distance moved (TDM) that occurred over 1-6 h post-LPS (Fig. 1g) and a decrease in FST immobility over $10-12 \mathrm{~h}$ post-LPS challenge (Fig. 1h). The time-dependent behavioral outcomes appeared to be associated with $\mathrm{NF \kappa B}$ activation in a tissue-specific manner. A comparative trajectory showed that dermal NFkB activation correlated with the early-phase where increased TDM was observed. In contrast, IL-PFC NFKB activation correlated with the late-phase where decreased immobility was observed (Fig. 1i).

\section{Two faces of GR in the inhibition of NFKB activity}

In the trajectory of dermal NFKB, we noticed a discontinuance during the middle-phase (Fig. 1i); this is likely due to the inhibitory actions of GR on $\mathrm{NF \kappa B}$, as evidenced by a dramatic increase in plasma CORT at $2 \mathrm{~h}$ post-LPS (Supplementary Fig. 5a). To demonstrate this, we performed dual monitoring of GR activity with the GRELuc2CP reporter (Fig. 2a) [16]. Unlike the differences shown in NFkB activation (Fig. 1e, i), GR activation showed no difference between the IL-PFC and dermis across all time points (Fig. 2b, c; tissue $\times$ time interaction: $F_{9,252}=0.93, P=0.50$ ), but significant GR activations were observed (time: $F_{9,252}=42.11, P<0.001$ ) during the middle and late-phase. As expected, the trajectory of GR was opposite to that of NFKB during the middle-phase, suggesting that the middle-phase GR activation plays a key role in modulating excessive inflammation upon binding to high levels of GC. In contrast, it seems that late-phase GR activity has no inhibitory action, as evidenced by similar trajectories of GR and $\mathrm{NF \kappa B}$ and consequent depressivelike behavior (Fig. 2d).
The conflicting results of GR inhibitory action on NFKB were corroborated by in vitro experiments with H19-7 cells. $\mathrm{TNF} \alpha$ treatment significantly increased GR and NFKB nuclear translocations and their corresponding activities (Fig. 2e, f), suggesting cytokine-induced GR activation. Interestingly, both CORT and $\mathrm{TNF} \alpha$ induced $\mathrm{SC} 35$-positive speckles (Fig. 2g), implying involvement of transcriptional mechanism in the TNF $\alpha$-driven gene regulation as well as CORT-driven gene regulation [21]. We also found that the activated $\mathrm{NF} \kappa \mathrm{B}$ induced by $\mathrm{TNF} \alpha$ was eradicated by the high dose of CORT treatment (Fig. 2h). Accordingly, in in vivo experiments with systemic LPS challenge, the transient depressive-like behavior during the late-phase was eliminated by CORT pre-treatment (Supplementary Fig. 6), suggesting a restored inhibitory action by CORT [22-24].

\section{Systemic blockade of GR activity leading to activation of NFKB in the IL-PFC}

Basal GR activity was blocked by RU486 before LPS treatment, to determine if low GR activity is sufficient to inhibit NFKB activity in the IL-PFC (Fig. 3a). As expected, repeated single-monitoring assays showed that GR activity was significantly reduced in the RU486-treated group compared with the control group during the early-phase (Fig. 3b; time $\times$ treatment: $F_{9,110}=6.78, P<0.001, P<$ 0.001 at 4 and $8 \mathrm{~h}$ ). Reversely, NFkB activity was significantly increased (Fig. 3c; time $\times$ treatment: $F_{9,99}=8.34$, $P<0.001 ; P<0.05$ at $1,2,4$, and $12 \mathrm{~h}$ ). Depressive-like behavior was also observed during the early and late-phases (Fig. 3d, e).

The rebound of GR activation after RU486 clearance seemed to be induced by cytokines, as shown in the latephase GR activity by LPS (Fig. 3b) because depressive-like behaviors were measured during this phase. In line with this, the rebound in GR activation was also observed in the RU486 experiments in ADX mice (Supplementary Fig. 7). In the test of a direct GR involvement in the IL-PFC using RU486 brain infusion, similar results of depressive-like behavior were obtained without a dramatic increase in plasma CORT compared to the LPS-treated group (Supplementary Fig. 8). Meanwhile, there were dramatic CORT increases in RU486/ LPS i.p. injection, irrespective of the phase (Supplementary Fig. 5b), as reported by previous studies [25-28].

\section{Transcriptional links to NFkB-GR signal interplay}

To gain transcriptional insight into the GR inhibitory action on NFKB in the middle phase, PCR analysis was used to investigate the negative correlation coefficients between eight GR-specific genes known to inhibit NFKB signaling [29-34] and 32 NFKB-response genes (Supplementary Table 1). Of the eight GR-specific genes, GILZ expression 
(a)

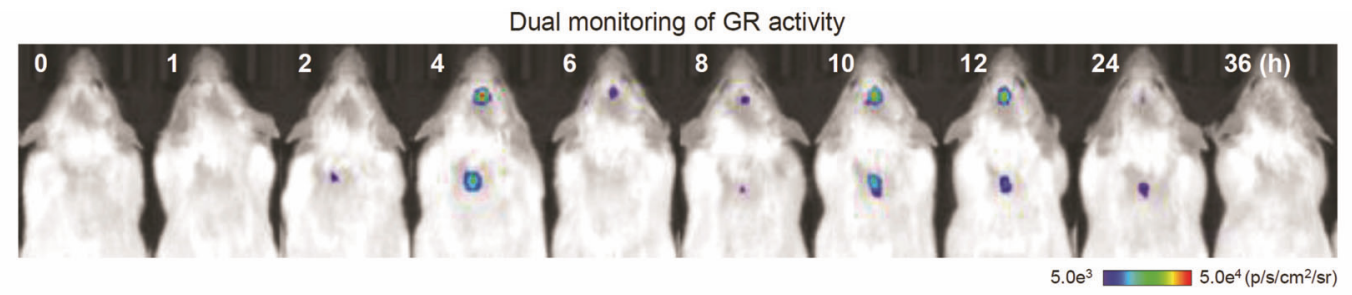

(b)

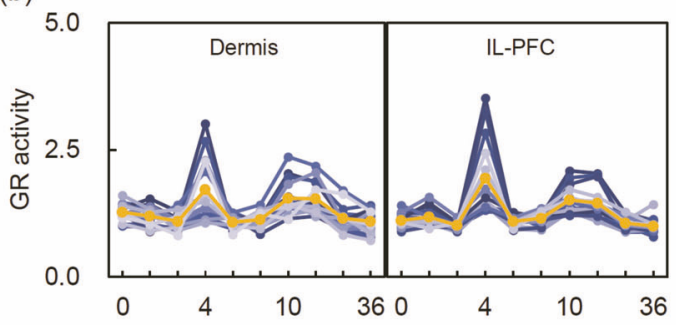

(c)

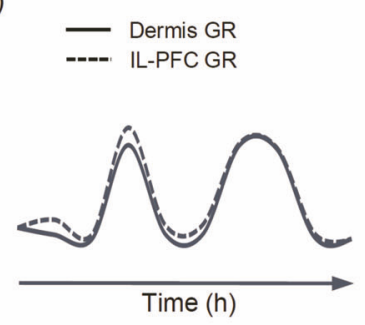

(g)

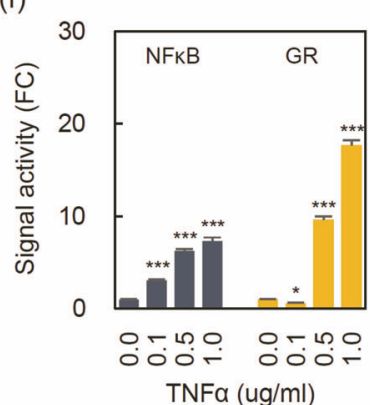

(d)

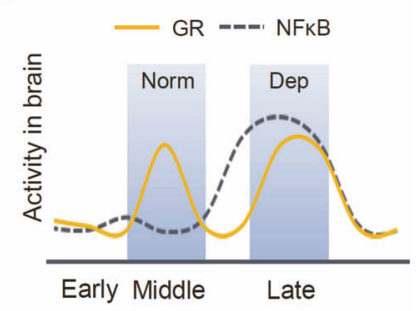

(h)

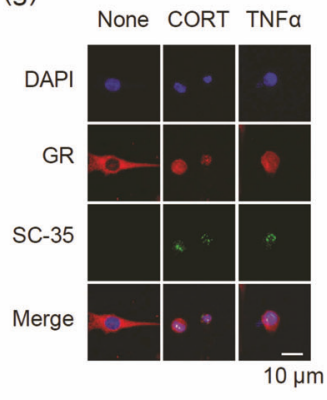

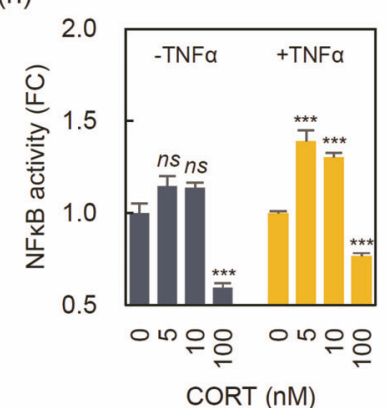

Fig. 2 Distinct GR involvement in the inhibition of NFкB activity. a Representative bioluminescent images (BLIs) of GR dual monitoring by the GRE-Luc2CP reporter. b Individual GR profiles of the dermis (left panel) and IL-PFC (right panel). The orange line represents the average GR activity at each time point $(n=15)$. $\mathbf{c}$ The trajectories of the two GR activities, and (d) the trajectories of the NFKB and GR activities in the IL-PFC. e Representative confocal images of nuclear GR translocation by TNF $\alpha$ in H19-7 cells. The cells were stained for GR (green) and p65 (red). $\mathbf{f}$ The effect of TNF $\alpha$ on NFKB and GR activities. To evaluate the effects, H19-7 cells were infected with each Luc2CP reporter and then incubated for $36 \mathrm{~h}$ in the presence of the indicated doses of $\mathrm{TNF} \alpha \quad(n=4 /$ group for in vitro tests).

significantly increased in the middle phase, but the other genes did not (Supplementary Fig. 9a). This might have resulted from individual variations due to mainly endpoint analysis. Correlation analysis with the same individual mice can increase statistics significance by reducing at least intraindividual variability. As shown in Fig. 4a, the correlation coefficient showed that the two GR-specific genes encoding for ANXA1 (24.17\%) and I $\mathrm{I} B \alpha(39.27 \%)$ were mostly negatively correlated. A time-lapse heat map with ten-time points also showed a negative correlation coefficient mainly in the ANXA1 and I $\mathrm{KB} \alpha$ (Fig. $4 \mathrm{~b}$ and Supplementary Fig. 10), but unexpectedly negative correlations spread across all periods. In an alternative analysis of four periods, however, negative correlation coefficients with seven NFKB-responsive genes were found primarily in the middle g Representative confocal images of nuclear GR translocation and SC35 as a nuclear speckle marker induced by CORT or TNF $\alpha$ treatment in H19-7 cells. The cells were stained for GR (red) and SC-35 (green). h The effects of CORT on NFKB activity. To evaluate the effects, H19-7 cells were infected with $\mathrm{NF \kappa B}$ Luc2CP reporter and then incubated for $36 \mathrm{~h}$ in the presence or absence of the TNF $\alpha$ by the presence of the indicated doses of CORT ( $n=4$ /group for in vitro test). Each signal activity was divided by an average of EF1 $\alpha$-Luc $2 \mathrm{CP}$ signals. Statistical significance was determined by Student's $t$-test $(* P<0.05, * * * P<0.001$ vs control). IL-PFC infralimbic prefrontal cortex; CORT corticosterone. Norm normal behavior; Dep depressivelike behavior (color figure online).

phase (Fig. 4c). These negative correlations were mostly converted to positive correlations by RU486 treatment (Fig. 4d) in the middle phase. These results suggest that two GR-specific genes, ANXA1 and I $\mathrm{KB} \alpha$, are involved in protecting depressive-like behavior through inhibition of $\mathrm{NF \kappa B}$ during the body-to-brain inflammatory spread.

\section{Effect of AAV-mediated gene silencing in the IL-PFC on depressive-like behavior by LPS}

We employed RNA interference to confirm the causative association of ANAX1 or I $\mathrm{I} B \alpha$ with the depressive-like behavior. After candidate shRNAs were confirmed by in vitro fluorescence and western bolt analyzes (Supplementary Fig. 11), the right IL-PFC of mice were unilaterally 


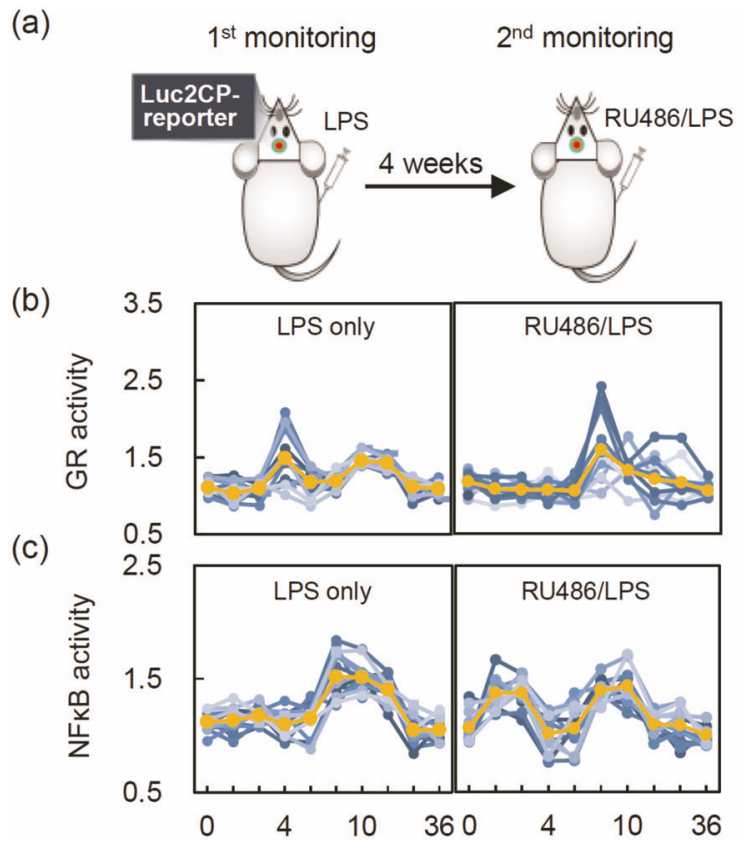

(d)
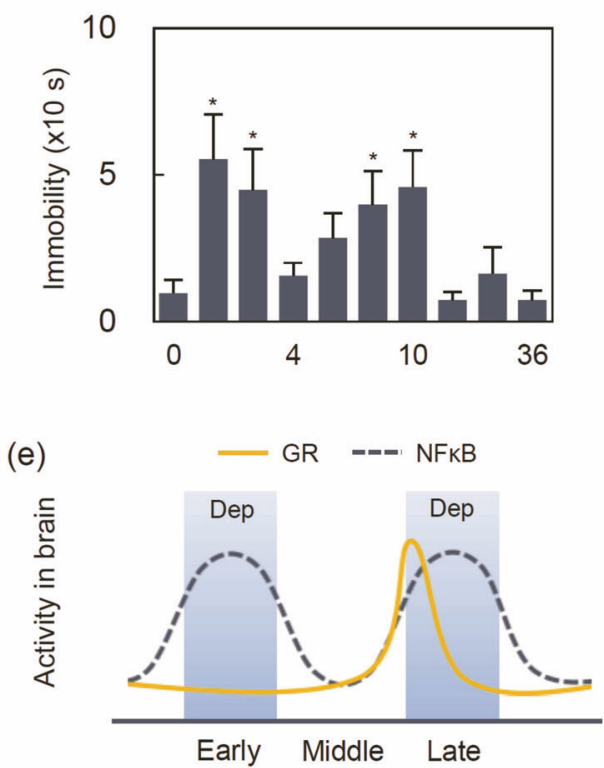

Fig. 3 RU486 induced early brain NFкB activation and corresponding depressive-like behavior. a Schematic illustrating repeated analysis with single-monitoring in IL-PFC. $\mathbf{b}$ Individual GR profiles of $1 \mathrm{mg} / \mathrm{kg}$ LPS (left panel) and $10 \mathrm{mg} / \mathrm{kg}$ RU $486+1 \mathrm{mg} / \mathrm{kg}$ LPS (right panel). c Individual NFKB profiles of $1 \mathrm{mg} / \mathrm{kg}$ LPS (left panel) and 10 $\mathrm{mg} / \mathrm{kg} \mathrm{RU} 486+1 \mathrm{mg} / \mathrm{kg}$ LPS (right panel). The orange line represents the average GR activity at each time point $(n=12)$. Time course of behavior for (d) immobility time in the FST. Data are represented as the mean \pm standard error of measurement $[n=8$ /group, except for 12 h post-LPS ( $n=7 /$ group)] (e) the trajectories of NFkB and GR activities in the LPS/RU486-treated mice. Statistical significance was determined by Student's $t$-test ( $* P<0.05$ vs control). IL-PFC infralimbic prefrontal cortex, LPS lipopolysaccharide, FST forced swimming test, Dep depressive-like behavior (color figure online). injected with AAV-scramble-shRNA, AAV-ANAX1shRNA, or AAV-IkB $\alpha$-shRNA vectors. Four weeks later, mice were i.p. injected with LPS and then the immobility in the FST was analyzed at $4 \mathrm{~h}$ post-LPS. Similar to the depressive-like behavior with RU486/LPS treatment, the silencing of ANAX1 increased immobility at $4 \mathrm{~h}$ post-LPS (Fig. 4e), indicating that ANXA1 is a key transcript in ILPFC for protection against neuroinflammation induced by systemic LPS [35-37]. However, no change was found in the mobility with IкB $\alpha$ knockdown mice (data not shown). The different behavioral outcomes between ANXA1 and I $\kappa \mathrm{B} \alpha$ may be due to the IL-PFC microenvironment with less effective ANAX1 action that suppresses neuroinflammation [38], or the insufficient IкB $\alpha$ knockdown with the unilateral injection that affects behavioral change. Taken together, we propose that the inhibitory action of GR on NFkB changes over time in the body-to-brain inflammatory spread (Fig. 4f and Supplementary movies 1,2 ).

\section{Discussion}

This study is the first to monitor in vivo temporal NFאB and GR activity to account for how the hypothalamic-pituitaryadrenal (HPA)-axis modulates the immune system in the body and brain $[39,40]$. The middle and late GRs were differentially involved in the inhibitory action on NFkB activity by a systemic inflammatory challenge; upon binding to high levels of GC, the middle-phase GR effectively inhibits NFkB, whereas the late-phase GR has no inhibitory action. Experiments with RU486 also revealed a cryptic mechanism that basal GC plays a protective role in the early brain inflammatory assault. Furthermore, by assessing gene silencing in the IL-PFC, we showed that ANAX1 plays an important role during brain inflammatory adaptation [41, 42].

A notable finding in our study was the activation of $\mathrm{NF \kappa B}$, which serves as a biological marker of the behavioral outcome. The most difficult riddle in behavioral research is linking signal activity with behavioral outcomes. Particularly, the behavioral relevance of in vivo NFKB activity is not well known. Our results of behavioraloutcome-based NFKB transition demonstrated that body and brain NFkB activation corresponded to sickness and depressive-like behaviors, respectively. This suggests a tissue-specific association with NFKB activation [43]. This depressive-like association was corroborated using RU486 experiments, in which $\mathrm{NF \kappa B}$ activation and consequent depressive-like behavior appeared in the early phase.

Another finding was the temporal involvement of the GR inhibitory action on NFKB. Given the inflammation and 
(a)

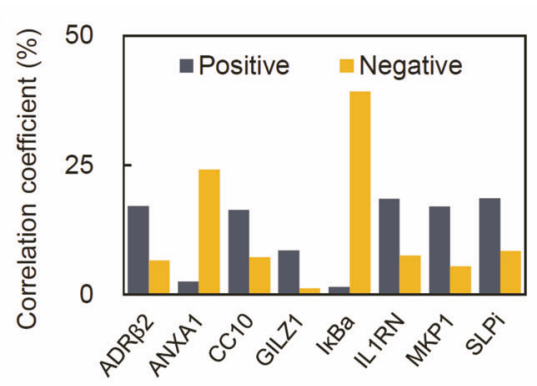

(b)

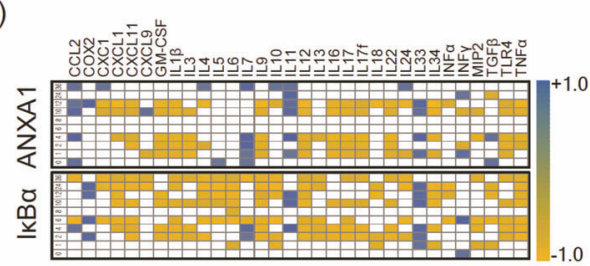

(e)

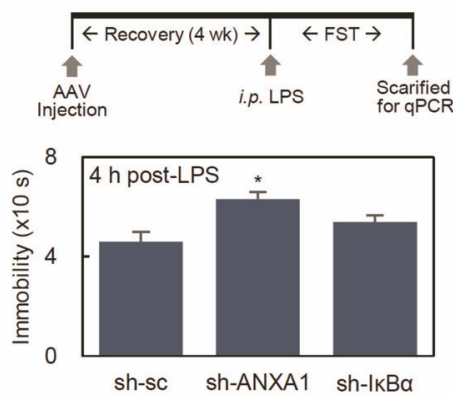

Fig. 4 Transcriptional analysis of NFкB-GR interplay with qPCR. a Percentages of correlation coefficient in NFkB-GR transcriptional interplay. b Time-lapse heat map of the correlation coefficients of 32 NFkB-response genes with ANAX1 and $\mathrm{I} \kappa \mathrm{B} \alpha(n=8 /$ group $)$. Temporal network connectivity of (c) LPS-treated mice ( $n=8 /$ group) and (d) RU486/LPS-treated mice [ $n=8$ /group except for $12 \mathrm{~h}$ post-LPS $(n$ $=7 /$ group)] with four periods. Periods were grouped according to the behavioral outcomes, and seven NFkB-responsive genes were selected for a clear correlation with ANAX1 and I $\mathrm{B} \alpha$ in the middle phase. The

hypercortisolism observed in depressed patients [44, 45], it is important to evaluate the impairment of the GR inhibitory function on $\mathrm{NFKB}$, a neurobiological mechanism for the depressive disorder [1]. From the in vivo NFkB-GR trajectory, we suggest that the HPA-axis plays a critical role in the temporal ability of GR to inhibit NFKB activity. For example, the middle-phase GR involved in normal behavior has been shown to remarkably inhibit NFkB through GR binding to high levels of CORT [46, 47]. In contrast, the late GR involved in depressive-like behavior is considered devoid of inhibitory as evidenced by the coexistence of GR and NFKB activation in the late phase. The loss of inhibitory action can be explained by GC resistance mediated by the selective accumulation of GR $\beta$ protein induced by TNF- $\alpha$ treatment [22]. However, we cannot rule out the possibility of direct antagonism of NFkB by GR through protein-protein interactions. This is because in vitro TNF $\alpha$ treatment significantly increases GR nuclear translocation (c)

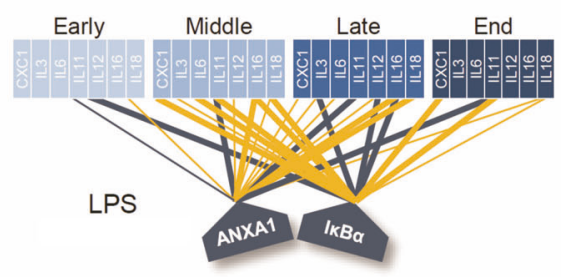

(d)

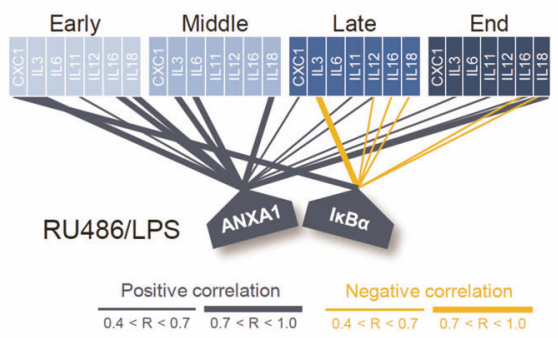

(f)

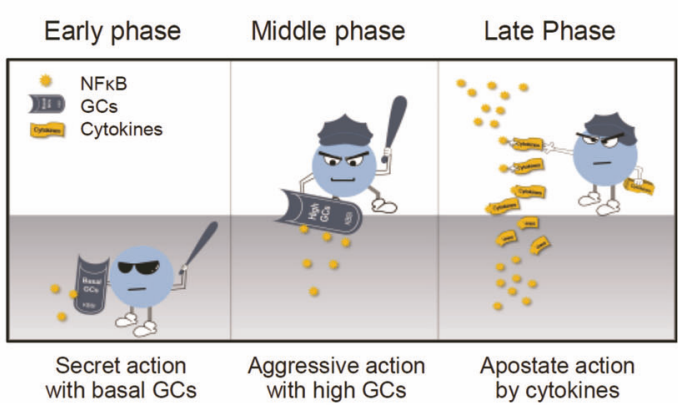

connecting lines are colored according to their correlation direction and specificity, as in the insert. e Experimental procedure and immobilization analysis of FST for AAV-based gene silencing in ILPFC. f Illustrations of the proposed model. GCs, glucocorticoids, seven NFkB-responsive genes; CXC1, IL3, IL6, IL11, IL12, IL16, and IL18. In correlation analysis, only the significant correlation coefficient $(P<0.05)$ of GraphPad Prism (GraphPad Prism software v7.04, Inc.) was used. Statistical significance was determined by Student's $t$ test ( $* P<0.05$ vs control for immobility analysis) (color figure online).

and its corresponding activity [23, 24, 48, 49]. In addition, TNF $\alpha$-activated NFkB was abolished by treatment with $100 \mathrm{nM}$ CORT in the H19-7 cells (Fig. 2g). This was confirmed by in vivo experiment with i.p. CORT injection, showing alleviated depressive-like behaviors in the late phase (Supplementary Fig. 6).

We also discovered the latent role of the basal HPA-axis in inhibitory action on NFKB activity by blocking GR activity with RU486 pretreatment in the early phase. Clinical evidence on the basal HPA-axis [50], knowing the psychiatric significance of basal GR activity can help determine why the basal HPA-axis is sometimes distorted, leading to stressrelated disorders, such as depression [51-53]. Thus, our study may provide unique insights on how to direct the HPA-axis of a depressed patient to cure the antidepressant-resistant depression caused by neuroinflammation.

One challenge faced in this study was the readouts of transcription results. The nonsignificant changes in the 
expression levels of GR-specific genes including genes modulating GR activity (i.e., GR, SGK1, and FKBP5), were expected to be upregulated during the middle phase; however, there were no changes except for GILZ expression. This could be explained by the endpoint PCR analysis and diverse transcriptional reactivity derived from various cells in the IL-PFC. Nevertheless, other possibilities, such as the decoupling of transcript expression and GR activity could not be ruled out, as described in our previous study in which fluoxetine had no effect on hippocampal GR protein expression for GR activation [1]. Another challenge was the different statistical significance between gene expression and network analyzes. Although network analysis showed negative correlation coefficients with ANXA1 and I $\mathrm{I} B \alpha$ in the middle phase, the gene expression levels were not increased. This could be explained by the statistical rigor, which could be performed using data from single individuals in the network analysis. The baseline is used as the value of interest but is considered noise in gene expression analysis. Also, similar values with gene expressions between groups are expected to perform different functions in the IL-PFC, particularly those with high individual variation. Finally, we also encountered certain difficulties in the readouts of transcriptional trajectory. The signal trajectory obtained with the reporter was clearly visible; however, it was difficult to obtain a clear trajectory with the GR specific genes in qPCR analysis. This may have been related to the different features of the detection method for signals and transcripts. Signals were monitored in a longitudinal analysis with reporters based on simple consensus sequences, generating a homogeneous trajectory. However, the endogenous promoter of the target gene is composed of various transcription factor (TF) binding elements [54, 55], resulting in complex changes in the spatiotemporal expression of the target gene [56]. Various cell types are also involved in the diversity of gene expression $[57,58]$. Naturally, the results of in vivo transcripts provide more physiologically relevant information; however, as we observed in our study, such data could increase the complexity of interpreting the link between transcriptional outcomes and behavioral phenotypes. The use of our reporter, which removed this complexity, clarified signal links.

The controversial issue was the difference in the reading of phenotypic outcomes in the same behavioral rodent test between research laboratories. For example, the immobility of FST has been widely used as a parameter to measure behavioral despair and helplessness as a parameter [59]; however, it has also been suggested as habituation $[60,61]$ or coping with the inescapable stressor $[62,63]$. This may be due to the complex features of human depression patients $[64,65]$ and thereby the lack of equivalence between animal models and depression [66]. In addition, the parameters of behavioral testing are known to be affected by strain, housing conditions, animal handling [67]. In antidepressant studies, the immobility of FST using ICR mice has been demonstrated as a depressive-like behavioral parameter, as evidenced by decreased immobility by fluoxetine (Supplementary Fig. 12) [64]. In contrast, OFT can be used to assess anxiety, exploration, and locomotor activity. These phenotypic outcomes can be discerned using different parameters such as the mouse's tendency to avoid the central areas as anxiety-like behaviors [68] and total distance traveled in the OFT for a parameter of motor activity that is interpreted as a sickness behavior [69]. Nevertheless, caution should be exercised when interpreting behavioral outcomes, as the parameters of the behavioral test may be inaccurate or outdated, as suggested by the de Kloet' group [62, 63].

The inability to investigate GR phosphorylation is a technical limitation; we could not analyze GR phosphorylation due to the discontinuation of commercial antibodies. Future studies should use antibodies for these two distinct GRs, particularly within its N-terminus (S203 and S211) $[1,70,71]$. Information on GR phosphorylation can provide detailed information on the molecular mechanisms underlying GR activation and different inhibitory GR actions on NFkB. Nevertheless, the technical strength of our study emanates from the high temporal resolution of the Luc2CP reporter, which allowed us to discern different $\mathrm{NF \kappa B}$ responses between the dermis and IL-PFC during the earlyphase. Analyzes using the reporters herein allow an integrated interpretation of the efficacy of drugs without further experimentation, such as the effects of RU486 on GR activity in the brain. The reporters can also be applied to a one-step drug assay, which is a simple method for testing drug effectiveness in the brain and is best suited for conceptual medical research.

In summary, this study sheds light on the role of the HPA-axis as an origin of inflammation-related depression. This information can be useful for guiding treatment by providing insight into how antidepressant-resistant depression occurs in the dysfunctional HPA-axis of depressed patients. Our in vivo signal-transition assay also provides a technical framework to elucidate how abnormalities in signaling pathways can lead to various psychiatry disorders.

Acknowledgements This research was supported by the Brain Research Program through the National Research Foundation of Korea (NRF) funded by the Ministry of Science, ICT \& Future Planning (NRF-2016M3C7A1905383).

\section{Compliance with ethical standards}

Conflict of interest The authors declare no competing financial interests. AFS is a co-founder and has equity in Corcept Therapeutics.

Publisher's note Springer Nature remains neutral with regard to jurisdictional claims in published maps and institutional affiliations. 
Open Access This article is licensed under a Creative Commons Attribution 4.0 International License, which permits use, sharing, adaptation, distribution and reproduction in any medium or format, as long as you give appropriate credit to the original author(s) and the source, provide a link to the Creative Commons license, and indicate if changes were made. The images or other third party material in this article are included in the article's Creative Commons license, unless indicated otherwise in a credit line to the material. If material is not included in the article's Creative Commons license and your intended use is not permitted by statutory regulation or exceeds the permitted use, you will need to obtain permission directly from the copyright holder. To view a copy of this license, visit http://creativecommons. org/licenses/by/4.0/.

\section{References}

1. Lee MS, Kim YH, Park WS, Park OK, Kwon SH, Hong KS, et al. Temporal variability of glucocorticoid receptor activity is functionally important for the therapeutic action of fluoxetine in the hippocampus. Mol Psychiatry. 2016;21:252-60.

2. McKay LI, Cidlowski JA. Molecular control of immune/inflammatory responses: interactions between nuclear factor-kappa B and steroid receptor-signaling pathways. Endocr Rev. 1999;20: 435-59.

3. Mo A, Mukamel EA, Davis FP, Luo C, Henry GL, Picard S, et al. Epigenomic signatures of neuronal diversity in the mammalian brain. Neuron. 2015;86:1369-84.

4. Tsang JS, Schwartzberg PL, Kotliarov Y, Biancotto A, Xie Z, Germain RN, et al. Global analyses of human immune variation reveal baseline predictors of postvaccination responses. Cell. 2014;157:499-513.

5. Jasinska AJ, Service S, Choi OW, DeYoung J, Grujic O, Kong SY, et al. Identification of brain transcriptional variation reproduced in peripheral blood: an approach for mapping brain expression traits. Hum Mol Genet. 2009;18:4415-27.

6. Johnson DA, Andrews GK, Xu W, Johnson JA. Activation of the antioxidant response element in primary cortical neuronal cultures derived from transgenic reporter mice. J Neurochem. 2002;81: 1233-41.

7. Wender PA, Goun EA, Jones LR, Pillow TH, Rothbard JB, Shinde R, et al. Real-time analysis of uptake and bioactivatable cleavage of luciferin-transporter conjugates in transgenic reporter mice. Proc Natl Acad Sci USA. 2007;104:10340-5.

8. Sudheimer K, Keller J, Gomez R, Tennakoon L, Reiss A, Garrett A, et al. Decreased hypothalamic functional connectivity with subgenual cortex in psychotic major depression. Neuropsychopharmacology. 2015;40:849-60.

9. Koenigs M, Grafman J. The functional neuroanatomy of depression: distinct roles for ventromedial and dorsolateral prefrontal cortex. Behav Brain Res. 2009;201:239-43.

10. Akhmedov D, Rajendran K, Mendoza-Rodriguez MG, Berdeaux R. Knock-in luciferase reporter mice for in vivo monitoring of CREB activity. PLoS ONE. 2016;11:e0158274.

11. Osorio FG, de la Rosa J, Freije JM. Luminescence-based in vivo monitoring of NF-kappaB activity through a gene delivery approach. Cell Commun Signal. 2013;11:19.

12. Karssen AM, Her S, Li JZ, Patel PD, Meng F, Bunney WE Jr., et al. Stress-induced changes in primate prefrontal profiles of gene expression. Mol Psychiatry. 2007;12:1089-102.

13. Drevets WC. Functional anatomical abnormalities in limbic and prefrontal cortical structures in major depression. Prog Brain Res. 2000;126:413-31.

14. Portou MJ, Baker D, Abraham D, Tsui J. The innate immune system, toll-like receptors and dermal wound healing: a review. Vasc Pharm. 2015;71:31-6.
15. Biesmans S, Meert TF, Bouwknecht JA, Acton PD, Davoodi N, De Haes $\mathrm{P}$, et al. Systemic immune activation leads to neuroinflammation and sickness behavior in mice. Mediators Inflamm. 2013;2013:271359.

16. Heo H, Jo J, Jung JI, Han YM, Lee S, Kim SR et al. Improved dynamic monitoring of transcriptional activity during longitudinal analysis in the mouse brain. Biol Open. 2019;8:bio037168.

17. Leclerc GM, Boockfor FR, Faught WJ, Frawley LS. Development of a destabilized firefly luciferase enzyme for measurement of gene expression. Biotechniques. 2000;29:590-1. 594-596, 598 passim

18. Maes M, Berk M, Goehler L, Song C, Anderson G, Galecki P, et al. Depression and sickness behavior are Janus-faced responses to shared inflammatory pathways. BMC Med. 2012;10:66.

19. Dantzer R, O'Connor JC, Freund GG, Johnson RW, Kelley KW. From inflammation to sickness and depression: when the immune system subjugates the brain. Nat Rev Neurosci. 2008;9:46-56.

20. D'Mello C, Swain MG. Immune-to-brain communication pathways in inflammation-associated sickness and depression. Curr Top Behav Neurosci. 2017;31:73-94.

21. Bryantsev AL, Chechenova MB, Shelden EA. Recruitment of phosphorylated small heat shock protein Hsp27 to nuclear speckles without stress. Exp Cell Res. 2007;313:195-209.

22. Webster JC, Oakley RH, Jewell CM, Cidlowski JA. Proinflammatory cytokines regulate human glucocorticoid receptor gene expression and lead to the accumulation of the dominant negative beta isoform: a mechanism for the generation of glucocorticoid resistance. Proc Natl Acad Sci USA. 2001;98:6865-70.

23. Pace TW, Hu F, Miller AH. Cytokine-effects on glucocorticoid receptor function: relevance to glucocorticoid resistance and the pathophysiology and treatment of major depression. Brain Behav Immun. 2007;21:9-19.

24. Hu A, Josephson MB, Diener BL, Nino G, Xu S, Paranjape C, et al. Pro-asthmatic cytokines regulate unliganded and liganddependent glucocorticoid receptor signaling in airway smooth muscle. PLoS One. 2013;8:e60452.

25. Ding J, da Silva MS, Lingeman J, Chen X, Shi Y, Han F, et al. Late glucocorticoid receptor antagonism changes the outcome of adult life stress. Psychoneuroendocrinology. 2019;107:169-78.

26. Bellavance MA, Rivest S. The HPA-immune axis and the immunomodulatory actions of glucocorticoids in the brain. Front Immunol. 2014;5:136.

27. Belanoff JK, Rothschild AJ, Cassidy F, DeBattista C, Baulieu EE, Schold C, et al. An open label trial of C-1073 (mifepristone) for psychotic major depression. Biol Psychiatry. 2002;52:386-92.

28. Ratka A, Sutanto W, Bloemers M, de Kloet ER. On the role of brain mineralocorticoid (type I) and glucocorticoid (type II) receptors in neuroendocrine regulation. Neuroendocrinology. 1989;50:117-23.

29. De Bosscher K, Vanden Berghe W, Haegeman G. The interplay between the glucocorticoid receptor and nuclear factor-kappaB or activator protein-1: molecular mechanisms for gene repression. Endocr Rev. 2003;24:488-522.

30. Barnes PJ. Anti-inflammatory actions of glucocorticoids: molecular mechanisms. Clin Sci. 1998;94:557-72.

31. Chinenov Y, Rogatsky I. Glucocorticoids and the innate immune system: crosstalk with the toll-like receptor signaling network. Mol Cell Endocrinol. 2007;275:30-42.

32. Newton R, Holden NS. Separating transrepression and transactivation: a distressing divorce for the glucocorticoid receptor? Mol Pharm. 2007;72:799-809.

33. Ishmael FT, Fang $\mathrm{X}$, Galdiero MR, Atasoy U, Rigby WF, Gorospe M, et al. Role of the RNA-binding protein tristetraprolin in glucocorticoid-mediated gene regulation. J Immunol. 2008;180: 8342-53. 
34. Eddleston J, Herschbach J, Wagelie-Steffen AL, Christiansen SC, Zuraw BL. The anti-inflammatory effect of glucocorticoids is mediated by glucocorticoid-induced leucine zipper in epithelial cells. J Allergy Clin Immunol. 2007;119:115-22.

35. Gavins FN, Dalli J, Flower RJ, Granger DN, Perretti M. Activation of the annexin 1 counter-regulatory circuit affords protection in the mouse brain microcirculation. FASEB J. 2007;21:1751-8.

36. Rothwell N, Allan S, Toulmond S. The role of interleukin 1 in acute neurodegeneration and stroke: pathophysiological and therapeutic implications. J Clin Investig. 1997;100:2648-52.

37. Lian H, Shim DJ, Gaddam SS, Rodriguez-Rivera J, Bitner BR, Pautler RG, et al. IkappaBalpha deficiency in brain leads to elevated basal neuroinflammation and attenuated response following traumatic brain injury: implications for functional recovery. Mol Neurodegener. 2012;7:47.

38. Senchenkova EY, Ansari J, Becker F, Vital SA, Al-Yafeai Z, Sparkenbaugh EM, et al. Novel role for the AnxA1-Fpr2/ALX signaling axis as a key regulator of platelet function to promote resolution of inflammation. Circulation. 2019;140:319-35.

39. McEwen BS. Redefining neuroendocrinology: epigenetics of brainbody communication over the life course. Front Neuroendocrinol. 2018;49:8-30.

40. Schobitz B, Reul JM, Holsboer F. The role of the hypothalamicpituitary-adrenocortical system during inflammatory conditions. Crit Rev Neurobiol. 1994;8:263-91.

41. McArthur S, Cristante E, Paterno M, Christian H, Roncaroli F, Gillies GE, et al. Annexin A1: a central player in the antiinflammatory and neuroprotective role of microglia. J Immunol. 2010;185:6317-28.

42. Ries M, Loiola R, Shah UN, Gentleman SM, Solito E, Sastre M. The anti-inflammatory Annexin A1 induces the clearance and degradation of the amyloid-beta peptide. J Neuroinflammation. 2016;13:234.

43. McEwen BS, Bulloch K. Epigenetic impact of the social and physical environment on brain and body. Metabolism. 2019;100S:153941.

44. Chrousos GP, Kino T. Glucocorticoid action networks and complex psychiatric and/or somatic disorders. Stress. 2007;10:213-9.

45. Raison CL, Miller AH. When not enough is too much: the role of insufficient glucocorticoid signaling in the pathophysiology of stress-related disorders. Am J Psychiatry. 2003;160:1554-65.

46. Beishuizen A, Thijs LG. Endotoxin and the hypothalamopituitary-adrenal (HPA) axis. J Endotoxin Res. 2003;9:3-24.

47. MacPhee IA, Antoni FA, Mason DW. Spontaneous recovery of rats from experimental allergic encephalomyelitis is dependent on regulation of the immune system by endogenous adrenal corticosteroids. J Exp Med. 1989;169:431-45.

48. Verhoog NJ, Du Toit A, Avenant C, Hapgood JP. Glucocorticoidindependent repression of tumor necrosis factor (TNF) alphastimulated interleukin (IL)-6 expression by the glucocorticoid receptor: a potential mechanism for protection against an excessive inflammatory response. J Biol Chem. 2011;286:19297-310.

49. Flandreau EI, Bourke $\mathrm{CH}$, Ressler KJ, Vale WW, Nemeroff $\mathrm{CB}$, Owens MJ. Escitalopram alters gene expression and HPA axis reactivity in rats following chronic overexpression of corticotropin-releasing factor from the central amygdala. Psychoneuroendocrinology. 2013;38:1349-61.

50. Tsigos C, Chrousos GP. Physiology of the hypothalamicpituitary-adrenal axis in health and dysregulation in psychiatric and autoimmune disorders. Endocrinol Metab Clin North Am. 1994;23:451-66.
51. Posener JA, Charles D, Veldhuis JD, Province MA, Williams GH, Schatzberg AF. Process irregularity of cortisol and adrenocorticotropin secretion in men with major depressive disorder. Psychoneuroendocrinology. 2004;29:1129-37.

52. Rothschild AJ, Samson JA, Bond TC, Luciana MM, Schildkraut JJ, Schatzberg AF. Hypothalamic-pituitary-adrenal axis activity and 1-year outcome in depression. Biol Psychiatry. 1993;34: 392-400.

53. Posener JA, DeBattista C, Williams GH, Chmura Kraemer H, Kalehzan BM, Schatzberg AF. 24-Hour monitoring of cortisol and corticotropin secretion in psychotic and nonpsychotic major depression. Arch Gen Psychiatry. 2000;57:755-60.

54. Keilwagen J, Grau J. Varying levels of complexity in transcription factor binding motifs. Nucleic Acids Res. 2015;43:e119.

55. Eggeling R. Disentangling transcription factor binding site complexity. Nucleic Acids Res. 2018;46:e121.

56. von Hippel PH. Increased subtlety of transcription factor binding increases complexity of genome regulation. Proc Natl Acad Sci USA. 2014;111:17344-5.

57. Smale ST, Natoli G. Transcriptional control of inflammatory responses. Cold Spring Harb Perspect Biol. 2014;6:a016261.

58. Lawrence KE, Hernandez LM, Bowman HC, Padgaonkar NT, Fuster E, Jack A, et al. Sex differences in functional connectivity of the salience, default mode, and central executive networks in youth with ASD. Cereb Cortex. 2020;30:5107-20.

59. Yankelevitch-Yahav R, Franko M, Huly A, Doron R. The forced swim test as a model of depressive-like behavior. J Vis Exp. 2015;97:52587.

60. Hawkins J, Hicks RA, Phillips N, Moore JD. Swimming rats and human depression. Nature. 1978;274:512-3.

61. Borsini F, Volterra G, Meli A. Does the behavioral "despair" test measure "despair"? Physiol Behav. 1986;38:385-6.

62. Molendijk ML, de Kloet ER. Coping with the forced swim stressor: current state-of-the-art. Behav Brain Res. 2019;364:1-10.

63. Molendijk ML, de Kloet ER. Immobility in the forced swim test is adaptive and does not reflect depression. Psychoneuroendocrinology. 2015;62:389-91.

64. Krishnan V, Nestler EJ. Animal models of depression: molecular perspectives. Curr Top Behav Neurosci. 2011;7:121-47.

65. Reardon S. Depression researchers rethink popular mouse swim tests. Nature. 2019;571:456-7.

66. Wong AH, Josselyn SA. Caution when diagnosing your mouse with schizophrenia: the use and misuse of model animals for understanding psychiatric disorders. Biol Psychiatry. 2016;79: $32-8$.

67. Turner KM, Burne TH. Interaction of genotype and environment: effect of strain and housing conditions on cognitive behavior in rodent models of schizophrenia. Front Behav Neurosci. 2013;7:97.

68. Montgomery KC, Monkman JA. The relation between fear and exploratory behavior. J Comp Physiol Psychol. 1955;48:132-6.

69. Van Meer P, Raber J. Mouse behavioural analysis in systems biology. Biochem J. 2005;389:593-610.

70. Chen W, Dang T, Blind RD, Wang Z, Cavasotto CN, Hittelman $\mathrm{AB}$, et al. Glucocorticoid receptor phosphorylation differentially affects target gene expression. Mol Endocrinol. 2008;22:1754-66.

71. Matthews L, Johnson J, Berry A, Trebble P, Cookson A, Spiller D, et al. Cell cycle phase regulates glucocorticoid receptor function. PLoS ONE. 2011;6:e22289. 